\title{
Animal cultures: how we've only seen the tip of the iceberg
}

\author{
Caroline Schuppli and Carel P. van Schaik \\ Department of Anthropology, University of Zürich, Winterthurerstrasse 190, 8057 Zürich, Switzerland \\ *Corresponding author: caroline.schuppli@aim.uzh.ch
}

\begin{abstract}
For humans we implicitly assume that the way we do things is the product of social learning and thus cultural. For animals, this conclusion requires proof. Here, we first review the most commonly used procedure for documenting animal culture: the method of exclusion, which charts geographic behavioral variation between populations as evidence for culture. Using published data, we show that, whereas it is an adequate proof of principle, the method of exclusion has major deficiencies when capturing cultural diversity and complexity. Therefore, we propose a new method, namely the direct counting of socially learned skills, which we apply to previously collected data on wild orangutans. This method reveals a far greater cultural repertoire among orangutans, and a different distribution of cultural elements among behavioral domains than found by the method of exclusion, as well as clear ecological correlates for most cultural elements. The widespread occurrence of social learning ability throughout the animal kingdom suggests that these conclusions also apply to many other species. Culture is most likely more widespread and pervasive than commonly thought and an important avenue to local adaptation. The complex and normative dimensions of culture seem unique to our species, but were most likely built upon a very broad, pre-existing cultural capacity that we inherited from our ancestors.
\end{abstract}

Key words: culture; social learning; method of exclusion; orangutans; animal cultural repertoires

Social media summary: A new way to assess animal cultures suggests that culture is far more widespread and pervasive than commonly thought.

\section{Introduction}

For a long time, culture was seen as an exclusively, and thus defining, human feature (Tylor, 1871). However, when evidence for culture-like variation was also found in a variety of non-human animal species, it became apparent that culture is part of a phylogenetic continuum rather than a uniquely human trait (Whiten, 2012). A clear definition of the phenomenon, universally agreed upon by different research fields, is called for, because the way we define culture has significant implications for where we will find it.

The oldest explicit definition by a cultural anthropologist regards culture as 'that complex whole which includes knowledge, beliefs, arts, morals, law, custom, and any other capabilities and habits acquired by man as a member of society' (Tylor, 1871). This human-oriented definition stresses that virtually everything we do, know or believe, as well as our institutions and technology, are a product of social learning and thus cultural (Braidwood, 1975). Notably, although the definition includes normative elements as products of culture, it does not claim that all culture is normative. It also leaves implicit how 'complex' culture has to be to qualify as such. In order to examine how human culture arose, biologists adapted this definition to non-human animals by describing culture as 'all behaviors

\footnotetext{
(c) The Author 2019. Published by Cambridge University Press. This is an Open Access article, distributed under the terms of the Creative Commons Attribution licence (http://creativecommons.org/licenses/by/4.0/), which permits unrestricted re-use, distribution, and reproduction in any medium, provided the original work is properly cited.
} 
and knowledge that are acquired and passed on within and between generations through social learning' (Boyd and Richerson, 1985). Hereafter, we refer to this as the minimal definition of culture.

Both definitions recognize that the precondition for culture is a demonstrated reliance on social learning, i.e. learning through observing, associating with or interacting with other individuals or their products (Heyes, 2012). However, whereas the minimal definition of culture as all socially learned skills and knowledge (at some point expressed in behavior) is still widely used by researchers studying culture in animals (Fragaszy and Perry, 2003; van Schaik, 2010; Whiten, 2017), some have argued that culture must be more than the product of social learning.

Thus, it has been proposed that socially learned behaviors can only qualify as cultural if they are normative, i.e. that an individual's deviant behaviors are sanctioned by its social group (Hill, 2009; McGrew, 2004). Others have argued that culture must be subject to cumulative change over time (Hill, 2009; Levinson, 2006; Tomasello et al., 1993), and/or transmitted by high-fidelity forms of social learning such as imitation or teaching (Galef, 1992). Effectively, this means that only behaviors exceeding a minimum level of complexity qualify as cultural. Yet others have required transmission across multiple generations as an essential criterion (sometimes also referred to as traditions; Perry, 2009a, b; Whiten and van Schaik, 2007). Finally, it has been suggested that culture requires socially learned variants in a variety of behavioral domains (Whiten and van Schaik, 2007).

In short, all definitions agree that skills and knowledge that are learned through a form of social learning are the quintessence of culture, irrespective of the actual social learning mechanism used. The more demanding definitions appear to reflect an attempt to distinguish the cultures of different taxa, especially humans from animals, although many habits we naturally call culture in humans are neither normative nor complex or diverse. Yet if we see culture as an overarching concept, it allows us to see normativity, complexity, stability or diversity as aspects of culture, each with a phylogenetic distribution. Thus, the minimal culture definition (Boyd and Richerson, 1985) allows comparisons across species and allows us to find out about the evolutionary roots of a trait in which our species undeniably outranges all others. This approach allows us to study culture from the bottom up rather than assuming that the human case represents the gold standard. Following the minimal definition of culture, we do not differentiate between different levels of social learning, because most skills and knowledge, often in humans as well, can be transferred through simple forms of social learning (e.g. enhancement or socially induced practice) and do not require high-fidelity forms of social learning (e.g. imitation or teaching; van Schaik et al., 2017). Accordingly, most behaviors that we will here consider as socially learned and thus cultural are within the innovative reach of an individual and not culture-dependent per se (Tennie et al., 2009).

\section{How to Measure Culture?}

When the minimal culture definition is applied to non-human animals, a significant problem arises. It is virtually impossible to demonstrate social transmission in nature, and where this was done unambiguously via field experiments, it was not clear whether the experimentally transmitted behaviors would persist over time (Reader and Biro, 2010; Whiten and Mesoudi, 2008). Thus, researchers have come to rely mainly on another approach, where they focus on one of the products of culture, namely geographic variation, to prove its presence.

If behaviors are acquired through social learning rather than invented independently, they are more likely to show geographic variation between populations because the underlying innovations are bound to be made only sporadically (Galef, 1976; Nishida, 1987). In humans, such contrasts between societies are automatically assumed to be the result of social transmission. However, for animals two alternative, non-exclusive explanations need to be excluded (McGrew and Tutin, 1978): (1) individually plastic responses to ecological differences between populations; and (2) population differences in genetic predispositions. This line of argumentation laid the foundation of the currently most commonly used tool to detect the presence of animal culture, namely the method of exclusion (MoE, also frequently referred to as the ethnographic method; Whiten et al., 1999) in which we classify a 
behavior as cultural if we can demonstrate a high prevalence in some populations but its absence in others, but also can reasonably rule out genetic or ecological factors as causes of this behavioral difference (Galef, 1976; Nishida, 1987).

Ruling out ecological effects underlying behavioral variation is difficult, and ruling out genetic effects is next to impossible. Yet where it can be done convincingly (e.g. Krützen et al., 2011; Lycett et al., 2009, 2011, but also Langergraber et al., 2010; Langergraber and Vigilant, 2011), we can identify cases where it is highly plausible that the observed variation is indeed the result of cultural transmission, especially when backed up by data on the social transmission process. The MoE is therefore a very useful proof of principle (van Schaik, 2010). Since for many species detailed data on individual behavior acquisition is lacking, the MoE has been used to suggest the presence of culture in species known to be capable of social learning in captivity. Accordingly, the MoE has revealed cultural variation in various primate, cetacean and bird species (Catchpole and Slater, 2003; Hohmann and Fruth, 2003; Krutzen et al., 2005; Ottoni and Izar, 2008; Perry et al., 2003; Riebel et al., 2015; Robbins et al., 2016; Santorelli et al., 2011; van Schaik et al., 2003a; Whitehead and Rendell, 2014; Whiten et al., 1999).

Although intended as a tool to detect the presence of culture (Galef, 1976; Nishida, 1987), the criteria of the MoE are now so ingrained that this operationalization has, to all practical purposes, reached the status of the definition of animal culture: cultural status is only assigned to behaviors that show geographic variation between populations (van Schaik, 2010). In other words, a 'cultural behavior is one that is transmitted repeatedly through social or observational learning to become a population-level characteristic' (Whiten et al., 1999). This perspective entails that culture is not an individual-level, but rather a population-level trait (see below).

For a variety of species, the MoE has been used to describe and compare cultural repertoire sizes (Robbins et al., 2016; Santorelli et al., 2011; van Schaik et al., 2003a; Whiten et al., 1999). However, we can list several shortcomings of the MoE (van Schaik et al., 2009) which conspire to produce biased and highly restrictive estimates of cultural repertoires.

First, social learning does not necessarily result in between-group heterogeneity. Identical ecological conditions are likely to bring about the same behavioral innovations in separate social units. Cultural transmission driven by social learning will thus inevitably produce similarities in behavioral repertoires between them, just as evolution driven by natural selection will often come up with the same genetic adaptations in similar environments. Whereas the latter is a widely acknowledged phenomenon, namely convergent evolution, the possibility of convergent culture is not yet widely acknowledged.

Second, the MoE ignores all behavioral variants that covary with ecological factors, even if the behaviors are in fact socially learned and thus cultural (van Schaik et al., 2009). Social learning will often produce behaviors that are adapted to a population's ecological conditions and help individuals to exploit natural resources (Byrne et al., 2004). Thus naturally, a substantial part of a species' cultural repertoire should indeed be linked to the local environment (Figure 1; Koops et al., 2014; Laland and Janik, 2006). Human culture exemplifies that ecological differences drastically shape cultural behavior. Ecology may make it impossible for certain socially learned behaviors to appear in some regions, but their presence elsewhere still reflects cultural processes.

Third, because the MoE excludes the majority of cultural variation with ecological components, it is heavily biased in the kinds of cultural variation it captures (see below). Whereas it detects disproportionately more behaviors of the social domain and complex dietary inventions such as tool use, it underestimates culturally transmitted basic subsistence skills. However, it is highly unlikely that the mechanisms of social learning are exclusively deployed for the acquisition of complex innovations; routine subsistence skills are almost certainly acquired in the same way.

Fourth, the MoE treats genetic differences underlying behavioral variation between populations as a deal breaker for culture. Genetic differences indeed often correlate with behavioral differences, which suggests that genetic differences may play a role in creating behavioral differences (Langergraber $e t$ al., 2010). Yet, in practice, genetic components do not rule out the presence of social learning (Laland and 


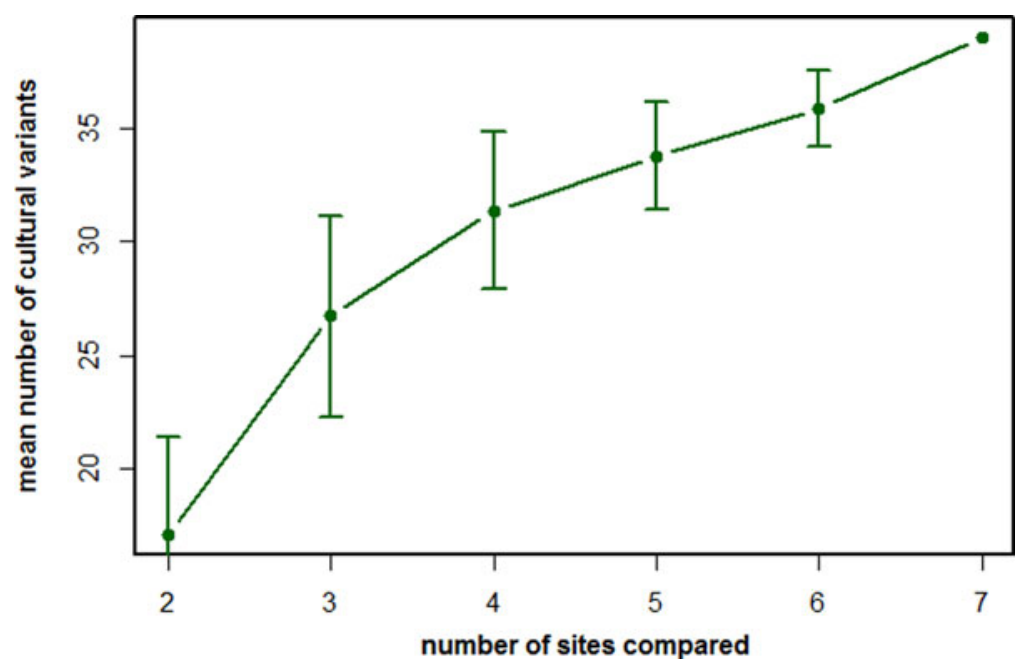

Figure 1. The number of recorded cultural variants as a function of populations being compared by the method of exclusion (MoE). The mean number of likely cultural variants described according to the criteria of the MoE by comparing the behavioral repertoires of an increasing number of chimpanzee populations. Based on data from Whiten et al. (1999).

Janik, 2006; Krützen et al., 2011). As with any complex phenotypic traits in nature, it is unlikely that behavioral repertoires can be strictly divided into innate and learned components. In particular, higher forms of social learning (Van Schaik, 2016; e.g. imitation, emulation and intentional teaching), which are based on a motivation to closely attend to the action of conspecifics, are likely to entail an element of genetically anchored social interest (Schuppli and van Schaik, 2019). According to the minimal definition of culture, behaviors based on genetic predispositions but expressed through socially mediated learning are to be considered as cultural.

Fifth, and perhaps most importantly, the number of cultural variants detected by the MoE is highly dependent on the number of populations we compare. Whereas a behavior $\mathrm{X}$ may well be shared between populations $\mathrm{A}$ and $\mathrm{B}$, it may not be shared with population $\mathrm{C}$. If we compare only populations $\mathrm{A}$ and $\mathrm{B}$, behavior $\mathrm{X}$ will not be considered to be cultural, because it is found in all of the populations compared. If we then add population $\mathrm{C}$ to this comparison, behavior $\mathrm{X}$ will suddenly count as cultural because it is not universally shared among all compared populations. This inevitably leads to an underestimation of cultural repertoires.

To illustrate this last point, let us turn to the most extensive list of cultural elements for any animal species published to date, namely the chimpanzees (Whiten et al., 1999). By comparing the behavioral repertoires of seven chimpanzee populations, a total of 39 behavioral variants were recognized, mainly composed of complex feeding skills (i.e. feeding techniques that contain multiple steps of processing, for example tool use) as well as several social behaviors. However, several variants are present at most sites and only lacking at a few sites. Consequently, if we only compared a subset of the number of populations, we would capture far fewer cultural variants (Figure 1). More importantly, the trajectory of the curve in Figure 1 suggests that, even by including all seven sites in the comparison, we are far from capturing the true chimpanzee cultural repertoire. Adding more populations into the comparison would probably lead to a further increase in the number of cultural variants. Accordingly, the repertoires obtained by the $\mathrm{MoE}$ are inherently incomplete.

The MoE is, without doubt, a great tool to detect likely cultural variation between populations. However, using geographic variation as the defining feature of culture makes it impossible to connect individual-level capacities to the trait. Furthermore, the MoE is a very poor technique to estimate either the size or the contents of cultural repertoires. If we applied this technique to humans, only a small and highly biased subset of what we naturally claim as part of our culture would remain, 
leaving out, for instance, most subsistence-related behaviors. Consequently, the lists of cultural variants described for non-human animal species in previous studies potentially vastly underestimate the actual sizes of their cultural repertoires.

\section{Describing Animal Culture without Relying on Geographic Variation}

To avoid the biases of the MoE, and capture culture irrespective of geographic variation, we here propose a novel way to estimate animal culture by directly capturing the process of cultural transmission, namely social learning. We propose to first identify and validate indicators of forms of social learning as actual means of social learning in a given species and then count the behaviors for which we can document that individuals deploy these indicators during skill acquisition. We call this procedure the method of counting socially learned skills (SLS).

\section{Counting socially learned skills in orangutans}

We test the SLS on wild orangutans, in which social interactions (including incidents of social learning) are rather easy to quantify because of the species' low level of sociability (van Schaik, 1999). Recently, we studied peering behavior (i.e. attentive and sustained close-range watching of the activities of a conspecific) in immature orangutans (Pongo sp.; Schuppli et al., 2016a). We found strong evidence that peering by immatures is an expression of socially induced learning, since it was followed by selective practice, decreased with growing competence of the peerer and was more and more directed at less familiar role models with increasing age of the immature peerers. Furthermore, peering rates increased with increasing rarity and complexity of the observed behavior.

Having validated peering as an index of social learning, we will first estimate the prevalence of social learning in orangutans by looking at how often individuals peer over their life time. By extrapolating cumulative peering counts based on known peering rates at different ages, we found that, over the course of their lives, Sumatran and Bornean orangutans (Pongo abelii and Pongo pygmaeus wurmbi) at the Suaq and Tuanan research sites peer around 38,000 and 9000 times (Figure 2). Individual's rates of peering are reduced to a minimum as adulthood is reached, at age 15 .

When we documented the peered-at behaviors our results showed that immatures peered for 195 and 122 different variants, including skills and knowledge elements (i.e. behavioral expressions of knowledge which shows no distinct skill, e.g. diet repertoires which are based on knowing that a certain fruit is edible), which we designated as probably SLS (Figure 3). This number is far greater than the 29 and 25 variants recognized by the MoE (van Schaik et al., 2009). Thus, when looking closely at great ape skill acquisition, it seems that immatures learn virtually all of their skills socially.

When we compare the repertoires captured by the SLS and MoE (Figure 3) it becomes apparent that they also differ in the composition of the resulting culture catalogs. The SLS detected most socially learned skills in the foraging domain (food items and feeding techniques), followed by nesting behaviors, social behaviors, moving habits, tool use variants and other behaviors. The MoE produced a more equal distribution of SLS over these different categories. Moreover, the variants captured by the MoE were mainly conspicuous high-complexity behaviors, which are easy to notice for the human observer because they contain multiple steps of distinct, coordinated actions (in the case of Suaq, three tool use variants and five other high-complexity feeding techniques which contain multiple steps of processing, three distinct and loud vocalizations and four distinct social behaviors). The SLS list, in contrast, was mainly composed of basic feeding, nesting, and social skills. Most of the peered-at behaviors showed clear ecological correlates (e.g. food items that are only present at one site).

\section{Comparing the Two Methods to Capture Animal Culture}

According to the minimal definition of culture (Boyd and Richerson, 1985), an individual's cultural repertoire is the sum of all socially learned skills and knowledge $\left(C_{1}=\sum S L S\right.$; Figure 3$)$. According 


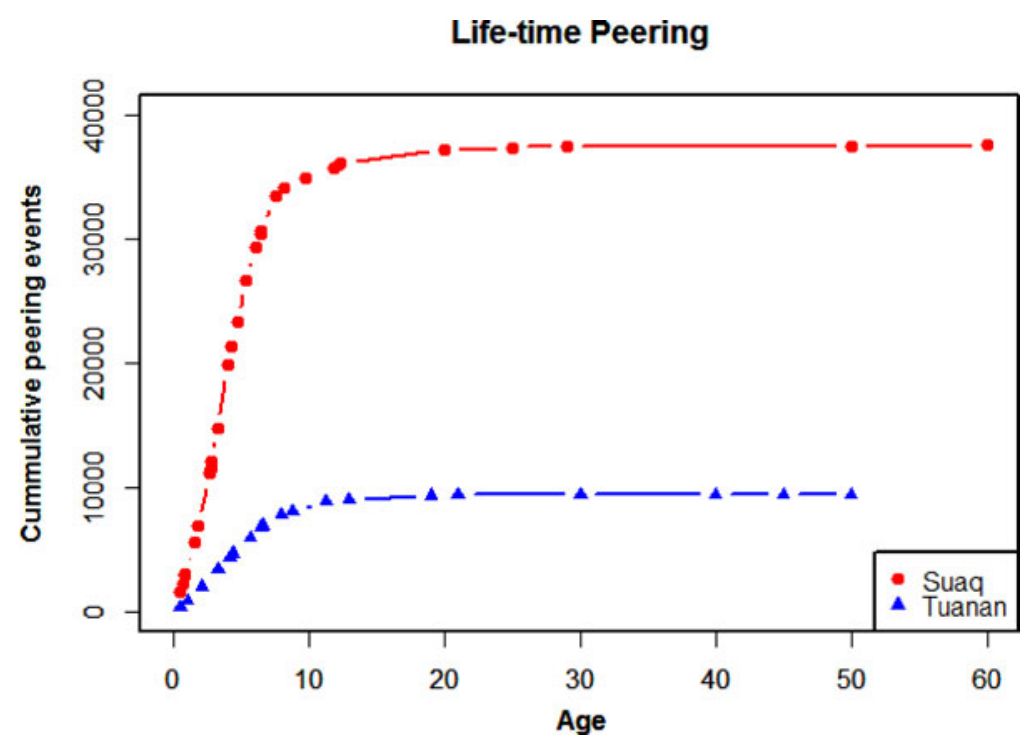

Figure 2. Lifetime orangutan peering. Extrapolated cumulative peering events over different ages for individuals at Suaq and Tuanan. See supplementary Table S1 for details.

to the population-level concept of culture (culture as all behaviors that show interpopulation geographic variation), it is the sum of all SLS minus the sum of all cultural behaviors shared between the compared populations $\left(C_{\mathrm{Var}}=\sum C_{1}-\sum C_{\mathrm{U}}\right.$, Figure 4). The difference between these two measures of cultural repertoire sizes is, among other factors, dependent on the innovation rate in relation to transmission efficiency.

The cultural repertoires recorded by the MoE should be a direct subset of the sum of all socially learned behaviors that show geographic variation because they disregard any variants with ecological or genetic correlates. We will disregard genetic predispositions, because linking single behaviors to specific genes remains impossible, most likely because such direct links do not exist. The strength of ecological influences on culture is a positive function of the difference we get from subtracting the cultural repertoires captured by the $\mathrm{MoE}\left(C_{\mathrm{ME}}\right)$ from the sum of all socially learned behaviors that show geographic variation $\left(C_{\mathrm{Var}}\right)$, i.e. $C_{\mathrm{Var}}-C_{\mathrm{ME}}=\sum C_{\mathrm{Ecol}}$ (Figure 4). A large difference implies that a lot of cultural variation is ecologically induced. Among orangutans, for instance, we find that many of their socially learned behaviors do indeed show ecological correlates such as food-processing skills or diet knowledge, which are highly dependent on the local availability of plant species.

So far, the effects of ecology on cultural variation have not yet been properly investigated. However, what has been shown is that ecological conditions have a strong effect on the two cornerstones of culture, namely innovation as the source of all culture and social learning as the underlying transmission mechanism of culture. First, innovation rates are heavily influenced by local ecology in terms of ecological opportunities (Koops et al., 2014; Reader et al., 2016; Spagnoletti et al., 2012; Torralvo et al., 2017). Second, social learning is influenced by ecological conditions such as terrestriality (Heldstab et al., 2016; Meulman et al., 2012; Sanz and Morgan, 2013; Spagnoletti et al., 2009; Visalberghi et al., 2005) or ecologically induced levels of sociability (Liker and Bókony, 2009; Roberts, 1996; Schuppli et al., 2017; van Schaik et al., 2003b). Furthermore, especially in long-lived species, increased learning efficiency through social learning is an important strategy to flexibly adapt to changing environments with local adaptations (Byrne et al., 2004; Laland and Janik, 2006). As such, cultural capacity is highly adaptive.

To assess repertoire sizes, the SLS may be a great improvement over the MoE, but it may still miss cultural variants. Indeed, only around half of the orangutan cultural variants detected by the MoE were 


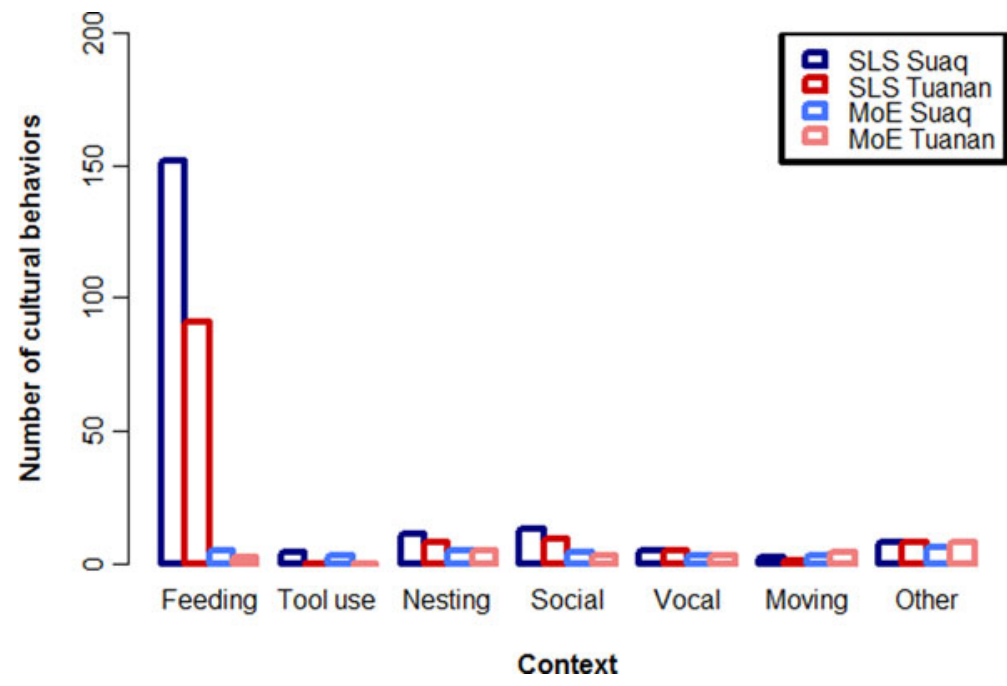

Figure 3. Comparing two methods to describe cultural repertoires. Number of cultural behaviors and knowledge elements caught by counting socially learned skills (SLS) vs relying on the MoE for the two orangutan populations at Suaq and Tuanan. See supplementary Tables S2 and S3 for the lists of peered at behaviors and behaviors caught by the MoE.

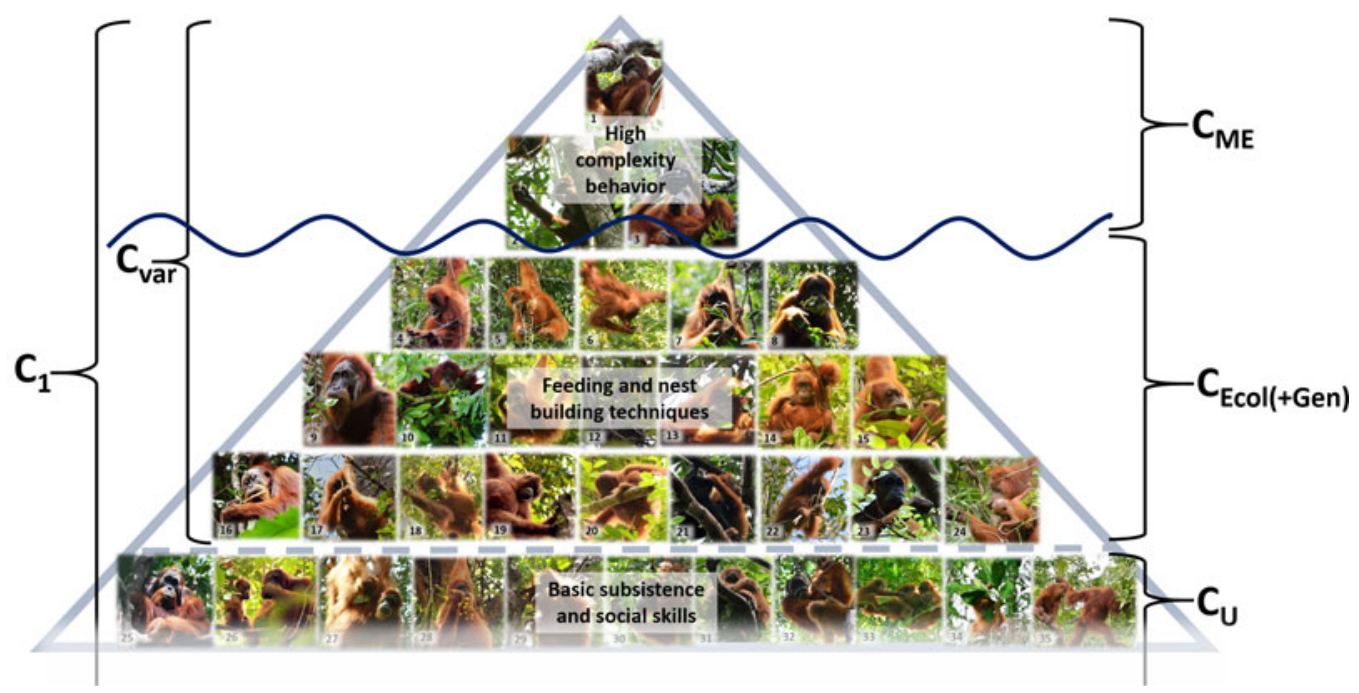

Figure 4. Different operationalizations of culture. The cultural behaviors captured by the $\operatorname{MoE}\left(C_{\mathrm{ME}}\right)$ are socially learned behaviors with a patchy geographic distribution but without ecological correlates (mostly conspicuous and/or high complexity behaviors such as tool use). The cultural behaviors with ecological correlates $\left(C_{\mathrm{Ecol}}\right)$ are socially learned behaviors that vary between populations because they are influenced by a population's local ecology (e.g. feeding skills). The sum of $C_{\mathrm{ME}}$ and $C_{\mathrm{Ecol}}$ are all socially learned behaviors that vary across populations $\left(C_{\mathrm{Var}}\right)$. Cultural universals $\left(C_{\mathrm{U}}\right)$ are socially learned behaviors and knowledge that we find consistently across populations (e.g. basic subsistence and social skills). The sum of all socially learned behaviors represents an individual's cultural knowledge $\left(C_{1}=C_{\mathrm{Var}}+C_{\mathrm{U}}\right)$. See supplementary Table S3 descriptions of the behaviors depicted on the pictures.

also captured by the SLS (18 of 29 for Suaq and 12 of 25 for Tuanan). The cultural variants for which we have no recorded peering events include behaviors whose transmission does not rely on peering (vocalizations and social interactions) or which are rarely performed. At both sites the lists of peered-at behaviors are still growing, despite massive follow efforts (around 19,000 hours for Suaq and 82,000 
hours for Tuanan). It takes thousands of observation hours to capture an individual's complete behavioral repertoire (Schuppli et al., 2016b). Also, even immatures who are still learning do not peer on every occasion of a behavior to be learned and we certainly miss a share of the peering events. In short, the current numbers still underestimate the real extent of the orangutan cultural repertoire.

\section{Discussion}

\section{The base of the great ape culture iceberg}

The orangutan example suggests that by relying on the MoE to assess cultural repertoires we have so far only discovered the tip of the great ape culture iceberg (i.e. $C_{1}>\mathrm{C}_{\mathrm{ME}}$; Figure 4). The MoE produces a biased sample of highly complex and conspicuous behaviors and dismisses a vast array of socially learned behaviors that covary with ecological factors. By counting socially learned skills, however, we are beginning to get to know the base of this iceberg. Cultural repertoires are mainly composed of basic, low-complexity subsistence skills, most of which show clear ecological correlates (e.g. knowledge of diet composition and processing techniques). Thus, a lot of (but not all) cultural variation may indeed be ecologically induced ( $C_{\mathrm{Ecol}}$ is a major part of $C_{1}$ and $C_{\mathrm{Var}}$ ).

At the same time, a systematic reliance on social learning under similar ecological conditions may very well lead to many universal cultural behavior patterns across populations. The most striking example in the orangutans for this is nest building: even though it is an orangutan universal, it takes young orangutans years of close observation and subsequent practice before they can build nests good enough to spend the night in (Schuppli et al., 2016a), and socially deprived young apes will never be able to do so (Bernstein, 1962; Videan, 2006). The basic construction of nests (a rim made of intertwined long branches) is highly comparable across different orangutan populations, presumably because it is the most latent solution to the problem (Tennie et al., 2009; high $C_{\mathrm{U}}$ but low $C_{\mathrm{Ecol}}$ ).

\section{How much culture is there in other animals?}

The points discussed above are unlikely to be true only for orangutans or great apes in general but most certainly apply to all species that rely on social learning. Although numerous species, including insects, fish, birds and mammals, are now known to be capable of social learning (reviewed by Galef and Laland, 2005; Rapaport and Brown, 2008; Reader and Biro, 2010; Whiten, 2017), for most, social learning has so far only been shown in captivity, which does not elucidate to what extent species indeed use this ability in the wild (Reader and Biro, 2010; Whiten and van de Waal, 2018). Even though behavioral scientists now increasingly acknowledge the role of social learning (van Schaik and Burkart, 2011; Tomasello, 1999; van Schaik et al., 2017), it is still widely treated as the rare and complex exception under the skill acquisition modes.

However, social learning can be quite simple given that many forms of social learning (e.g. enhancement or facilitation) do not require higher forms of cognition but nonetheless produce faithful behavioral copies owing to shared affordances. Furthermore, from the perspective of naïve immatures, a strong reliance on social learning is highly adaptive because social learning is less dangerous and more efficient than independent learning: it reduces the risk of getting injured or poisoned, increases learning speed by allowing the learning individual to benefit from what others have figured out before and increases the signal strength of relevant information (van Schaik and Burkart, 2011). Social learning thus allows for the fast acquisition of skills and the acquisition of more complex skills, and naïve individuals will benefit from choosing this option whenever they can. As such, we expect social learning to be most prominent in species with contact between generations, high social tolerance toward immatures, and an extended period of immaturity.

Over the last two decades it has become increasingly clear that social learning is indeed an important means of natural skill acquisition for many mammal and bird species, as evidenced in inherited dietary specializations, selective observations of skilled individuals, master apprentice interactions, 
effects of the presence of role models on foraging success or links between social networks and skill repertoires (Coelho et al., 2015; Estes et al., 2003; Griesser and Suzuki, 2016; Guinet and Bouvier, 1995; Hobaiter et al., 2014; Kitowski, 2009; Krutzen et al., 2005; Lonsdorf, 2006; Mann et al., 2007; Matsuzawa et al., 2001; Ottoni et al., 2005; Rapaport and Brown, 2008; Schuppli et al., 2016a). Direct observations of the spread of recently made innovations through social groups are bound to be rare but have been made in natural populations (Allen et al., 2013; Hobaiter et al., 2014; Kendal et al., 2010). Interspecific cross-fostering experiments, be they designed or accidental, although both quite rare, have impressively demonstrated the pervasiveness of social learning of life's skills (Rowley and Chapman, 1986; Sheppard et al., 2018; Slagsvold and Wiebe, 2007; Warner, 1988).

Culture is therefore likely to be pervasive in all species that pass on knowledge and skills socially. However, most of these species' skills will show little or no geographic variation, except for the most complex skills, which are the least likely to be invented and retained. In several species, the acquisition of basic foraging skills was shown to be socially mediated: in aye-ayes (Daubentonia madagascariensis), for example, immatures learn tap-foraging - for which they even have morphological specializations far less readily in the absence of adult role models (Krakauer, 2005).

Since social learning can be very simple, culture does not require a large brain and it is therefore unlikely to be a hallmark of cognitive complexity (Byrne et al., 2004; Laland and Hoppitt, 2003), although the efficiency of cultural transmission may also favor the evolution of greater investment in brains (van Schaik and Burkart, 2011).

\section{Remaining challenges in the animal culture debate}

Detecting animal culture irrespective of geographic variation is challenging and may not always be possible. Aside from peering, social learning can also happen via observation at longer distances, socially induced encounters with environmental features and acoustic transmission. Thus, in order to be able to draw conclusions about and compare cultural repertoires across species, it is crucial to find appropriate ways to detect social learning according to the species' main transmission mode as well as to take different transmission modes into account. The SLS will thus most likely only rarely produce integral cultural repertoires. In most cases, however, it will be able to lift a significant part of the so far hidden base of the culture iceberg above the surface.

\section{Implications for human culture}

Most elements which we nowadays naturally call the product of human culture can be found across the globe and are thus human universals. In this time of increasing connectedness and global exchange even the most complex human innovations often quickly reach the status of universals and would not be recognized as socially learned innovations by their geographic distribution. Yet everyone would agree that these innovations are an important part of our cultural repertoire.

What differentiates animal from human culture is the lack of normativity, the virtual absence of cumulative culture and the enormous diversity of human cultural elements (Laland and Galef, 2009; Whiten, 2017; Whiten and van Schaik, 2007). These three features seem to remain a hallmark of human culture and seem to be linked to the evolution of our species' skill-intensive, technologydependent foraging niche (van Schaik et al., 2019; Laland, 2017). However, the unique human cultural constellation was built on a surprisingly broad and evolutionarily deep foundation.

\section{Conclusions}

In sum, the true scope of animal culture will always be hard to estimate, but the most likely scenario is that what we have discovered so far using the MoE is only the tip of the animal cultural iceberg. Given that for most species social learning is the default mode of learning rather than the exception, repertoires of cultural behaviors are very likely to exceed current estimates. A wide spread of culture is in 
line with the notion that cultural capacity is an important tool that allows species to flexibly adapt to changing environments. If we intend to engage in a fair comparison with humans, we have to list a species' complete repertoire of socially learned behaviors. Given that the right technique to capture social learning can be developed (dependent on the modality of social learning of each species), we will be able to compare the size and content of cultural repertoires across species. In the case of the great apes, culture seems to pervade virtually all aspects of their life, making them fundamentally as cultural as humans, just not cumulative, complex or normative.

Supplementary material. The supplementary material for this article can be found at https://oi.org/10.1017/ehs.2019.1

Author ORCIDs. (D) Caroline Schuppli, 0000-0001-6318-2815; Carel van Schaik, 0000-0001-5738-4509.

Acknowledgements. We thank Maria van Noordwijk, Claudio Tennie and Andy Whiten for fruitful discussions on the topic of this paper. In terms of the orangutan data we acknowledge all students, volunteers and local field assistants involved in the collection of standard behavioral data for the long-term databases of Suaq Balimbing and Tuanan. We gratefully acknowledge the Indonesian Institute of Science, the Indonesian State Ministry for Research and Technology, the Director General Departemen Kehutanan, Departemen Dalam Negri, the local governments in Central Kalimantan and South Aceh, the BKSDA Palangkaraya, the Bornean Orangutan Survival Foundation and Mawas in Palangkaraya as well as the Sumatran orangutan conservation Program and Taman Nasional Gunung Leuser in Medan, for their permission and support to conduct this research. We also thank the Fakultas Biologi Universitas Nasional in Jakarta for their collaboration and support for the Tuanan project. We are particularly grateful to Dr Suci Utami Atmoko and Dr Tatang Mitra Setia for their expertise, support and collaboration.

Data Availability Statement. All data used for the analyses of this article can be found in the Supplementary Material (Tables S1-S3) and the published literature (indicated in the manuscript).

Authors' contributions. CS collected most of the peering data, did all analyses, and wrote and co-conceptualized the manuscript. CvS conceptualized and co-wrote the manuscript.

Competing interests. The authors declare that they have no competing interests.

Financial support. This work is supported by Swiss National Science Foundation (grant no. 310030B_160363/1), the Department of Anthropology of the University of Zürich, A.H. Schultz Foundation and the Leakey foundation (primate field site grant).

Ethical Statement. As a strictly observational study on wild animals, there was no interaction with our study animals in any way. The research protocols were approved by the Ministry of Research and Technology and complied with the legal requirements of Indonesia.

\section{References}

Allen J, Weinrich M, Hoppitt W and Rendell L (2013). Network-based diffusion analysis reveals cultural transmission of lobtail feeding in humpback whales. Science 340(6131), 485-488.

Bernstein IS (1962). Response to nesting materials of wildborn and captive-born chimpanzees. Animal Behaviour 10(1-2), 1-6.

Boyd R and Richerson PJ (1985). Culture and the Evolutionary Process. Chicago: University of Chicago Press.

Braidwood RJ (1975). Prehistoric Men. Glenview: Scott Foresman.

Byrne RW, Barnard PJ, Davidson I, Janik VM, McGrew WC, Miklosi A and Wiessner P (2004). Understanding culture across species. Trends in Cognitive Sciences 8(8), 341-346.

Catchpole CK and Slater PJ (2003). Bird Song: Biological Themes and Variations. Cambridge: Cambridge University Press.

Coelho CG, Falotico T, Izar P, Mannu M, Resende BD, Siqueira JO and Ottoni EB (2015). Social learning strategies for nutcracking by tufted capuchin monkeys (Sapajus spp.). Animal Cognition 18(4), 911-919, https://doi:10.1007/s10071-015-0861-5

Estes JA, Riedman ML, Staedler MM, Tinker MT and Lyon BE (2003). Individual variation in prey selection by sea otters: patterns, causes and implications. Journal of Animal Ecology 72(1), 144-155, https://doi:10.1046/j.1365-2656.2003.00690.x

Fragaszy D and Perry S (2003). Towards a biology of traditions. In Fragaszy D and Perry S (eds), The Biology of Traditions: Models and Evidence. Cambridge: Cambridge University Press, pp. 1-32.

Galef BG (1976). Social transmission of acquired behavior: a discussion of tradition and social learning in vertebrates. In Rosenblatt JS, Hinde RA, Shaw E and Beer C (eds), Advances in the Study of Behavior. New York: Academic Press, Vol. 6, pp. 77-100.

Galef BG (1992). The question of animal culture. Human Nature 3, 157-178. 
Galef BG and Laland KN (2005). Social learning in animals: empirical studies and theoretical models. Bioscience 55(6), 489499, https://doi:10.1641/0006-3568(2005)055[0489:sliaes]2.0.co;2

Griesser M and Suzuki TN (2016). Kinship modulates the attention of naive individuals to the mobbing behaviour of role models. Animal Behaviour 112, 83-91, https://doi:10.1016/j.anbehav.2015.11.020

Guinet C and Bouvier J (1995). Development of intentional stranding hunting techniques in killer whale (Orcinus-Orca) calves at Crozet archipelago. Canadian Journal of Zoology - Revue Canadienne De Zoologie 73(1), 27-33, https:// doi:10.1139/z95-004

Heldstab SA, Kosonen ZK, Koski SE, Burkart JM, van Schaik CP and Isler K (2016). Manipulation complexity in primates coevolved with brain size and terrestriality. Scientific Reports 6, 24528, https://doi:10.1038/srep24528

Heyes C (2012). What's social about social learning? Journal of Comparative Psychology 126(2), 193-202, https://doi:10.1037/ a0025180

Hill KR (2009). Animal 'culture'. In Laland KN and Galef BG (eds), The Question of Animal Culture. Cambridge, MA: Harvard University Press, pp. 269-287.

Hobaiter C, Poisot T, Zuberbuehler K, Hoppitt W and Gruber T (2014). Social network analysis shows direct evidence for social transmission of tool use in wild chimpanzees. Plos Biology 12(9), https://oi:10.1371/journal.pbio.1001960

Hohmann G and Fruth B (2003). Culture in bonobos? Between-species and within-species variation in behavior. Current Anthropology 44(4), 563-571.

Kendal RL, Custance DM, Kendal JR, Vale G, Stoinski TS, Rakotomalala NL and Rasamimanana H (2010). Evidence for social learning in wild lemurs (Lemur catta). Learning \& Behavior 38(3), 220-234.

Kitowski I (2009). Social learning of hunting skills in juvenile marsh harriers Circus aeruginosus. Journal of Ethology 27(3), 327-332, https://doi:10.1007/s10164-008-0123-y

Koops K, Visalberghi E and van Schaik CP (2014). The ecology of primate material culture. Biology Letters 10, 20140508.

Krakauer EB (2005). Development of Aye-Aye (Daubentonia madagascariensis) Foraging Skills: Independent Exploration and Social Learning. Durham NC: Duke University.

Krutzen M, Mann J, Heithaus MR, Connor RC, Bejder L and Sherwin WB (2005). Cultural transmission of tool use in bottlenose dolphins. Proceedings of the National Aacademy of Sciences USA 102(25), 8939-8943, https://doi:10.1073/pnas. 0500232102

Krützen M, Willems EP and van Schaik CP (2011). Culture and geographic variation in orangutan behavior. Current Biology 21, 1808-1812.

Laland KN (2017). Darwin's Unfinished Symphony: How Culture Made the Human Mind. Princeton, NJ: Princeton University Press.

Laland KN and Galef BG (2009). The Question of Animal Culture. Cambridge, MA: Harvard University Press.

Laland KN and Hoppitt W (2003). Do animals have culture? Evolutionary Anthropology 12, 150-159.

Laland KN and Janik VM (2006). The animal cultures debate. Trends in Ecology and Evolution 21, 542-547.

Langergraber KE and Vigilant L (2011). Genetic differences cannot be excluded from generating behavioural differences among chimpanzee groups. Proceedings of the Royal Society B: Biological Sciences 278(1715), 2094-2095.

Langergraber KE, Boesch C, Inoue E, Inoue-Murayama M, Mitani JC, Nishida T, Wrangham RW (2010). Genetic and 'cultural' similarity in wild chimpanzees. Proceedings of the Royal Society B: Biological Sciences 278(1704), 408-416.

Levinson SC (2006). Introduction: The Evolution of Culture in a Microcosm, Levinson SC and Jaisson ((eds). Cambridge, MA: MIT Press.

Liker A and Bókony V (2009). Larger groups are more successful in innovative problem solving in house sparrows. Proceedings of the National Academy of Sciences 106(19), 7893-7898, https://doi:10.1073/pnas.0900042106

Lonsdorf E (2006). What is the role of mothers in the acquisition of termite-fishing behaviors in wild chimpanzees (Pan troglodytes schweinfurthii)? Animal Cognition 9(1), 36-46.

Lycett SJ, Collard M and McGrew WC (2009). Cladistic analyses of behavioural variation in wild Pan troglodytes: exploring the chimpanzee culture hypothesis. Journal of Human Evolution 57, 337-349.

Lycett SJ, Collard M and McGrew WC (2011). Correlations between genetic and behavioural dissimilarities in wild chimpanzees (Pan troglodytes) do not undermine the case for culture. Proceedings of the Royal Society B: Biological Sciences 278 (1715), 2091-2093.

Mann J, Sargeant BL and Minor M (2007). Calf inspections of fish catches in bottlenose dolphins (Tursiops sp.): opportunities for oblique social learning? Marine Mammal Science 23(1), 197-202, https://doi:10.1111/j.1748-7692.2006.00087.x

Matsuzawa T, Biro D, Humle T, Inoue-Nakamura N, Tonooka R and Yamakoshi G (2001). Emergence of culture in wild chimpanzees: education by master-apprenticeship. In Matsuzawa T (ed.), Primate Origins of Human Cognition and Behavior. Tokyo: Springer, pp. 557-574.

McGrew WC (2004). The Cultured Chimpanzee: Reflections on Cultural Primatology. Cambridge: Cambridge University Press.

McGrew WC and Tutin CEG (1978). Evidence for a social custom in wild chimpanzees? Man 13, $234-251$.

Meulman EJ, Sanz CM, Visalberghi E and van Schaik CP (2012). The role of terrestriality in promoting primate technology. Evolutionary Anthropology 21(2), 58-68. 
Nishida T (1987). Local traditions and cultural transmission. In Smuts BB, Cheney DL, Seyfarth RM, Wrangham RW and Struhsaker TT (eds), Primate Societies. Chicago, IL: University of Chicago Press, pp. 462-474.

Ottoni E and Izar P (2008). Capuchin monkey tool use: overview and implications. Evolutionary Anthropology 17, $171-178$.

Ottoni EB, de Resende BD and Izar P (2005). Watching the best nutcrackers: what capuchin monkeys (Cebus apella) know about others' tool-using skills. Animal Cognition 8(4), 215-219, https://doi:10.1007/s10071-004-0245-8

Perry S (2009a). Are nonhuman primates likely to exhibit cultural capacities like those of humans? In Laland KN and Galef BG (eds), The Question of Animal Culture. Cambrdige, MA: Harvard University Press, pp. 247-268.

Perry S (2009b). Socia influence and the development of food processing techniques in wild white-faced cauchin monkeys (Cebus capucinus) at Lomas Barbudal, Costa Rica. American Journal of Primatology 71, 99-99.

Perry S, Baker M, Fedigan L, Gros-Louis J, Jack K, Mackinnon KC, Rose LM (2003). Social conventions in wild whitefaced capuchin monkeys: evidence for traditions in a neotropical primate. Current Anthropology 44, 214-268.

Rapaport LG and Brown GR (2008). Social influences on foraging behavior in young nonhuman primates: learning what, where, and how to eat. Evolutionary Anthropology 17(4), 189-201, https://doi:10.1002/evan.20180

Reader SM and Biro D (2010). Experimental identification of social learning in wild animals. Learning \& Behavior 38(3), 265-283, https://doi:10.3758/lb.38.3.265

Reader SM, Morand-Ferron J and Flynn E (2016). Animal and human innovation: novel problems and novel solutions. Philosophical Transactions of the Royal Society B: Biological Sciences 371, 20150182.

Riebel K, Lachlan RF and Slater PJ (2015). Learning and cultural transmission in chaffinch song Advances in the Study of Behavior. Oxford: Elsevier, Vol. 47, pp. 181-227.

Robbins MM, Ando C, Fawcett KA, Grueter CC, Hedwig D, Iwata Y, Stoinski TS (2016). Behavioral variation in gorillas: evidence of potential cultural traits. PloS One 11(9), e0160483.

Roberts G (1996). Why individual vigilance declines as group size increases. Animal Behaviour 51, 1077-1086, https://doi:10. 1006/anbe.1996.0109

Rowley I and Chapman G (1986). Cross-fostering, imprinting and learning in two sympatric species of cockatoo. Behaviour 96, 1-16.

Santorelli CJ, Schaffner CM, Campbell CJ, Notman H, Pavelka MS, Weghorst JA and Aureli F (2011). Traditions in spider moonkeys are biased towards the social domain. PloS One 6(2), e16863.

Sanz CM and Morgan DB (2013). Ecological and social correlates of chimpanzee tool use. Philosophical Transactions of the Royal Society B: Biological Sciences 368(1630), 20120416.

Schuppli C and van Schaik C (2019). Social learning among wild orangutans: is it affective? In Clément F and Dukes D (eds), Foundations of Affective Social Learning: Conceptualising the Transmission of Social Value. Cambridge: Cambridge University Press, in press.

Schuppli C, Meulman E, Forss SIF, Aprilinayati F, Van Noordwijk MA and Van Schaik CP (2016a). Observational social learning and socially induced practice of routine skills in wild immature orang-utans. Animal Behaviour 119, 87-98, https://doi:10.1016/j.anbehav.2016.06.014

Schuppli C, Forss SI, Meulman EJ, Zweifel N, Lee KC, Rukmana E, van Schaik CP (2016b). Development of foraging skills in two orangutan populations: needing to learn or needing to grow? Frontiers in Zoology 13(1), 43.

Schuppli C, Forss S, Meulman E, Atmoko SU, Noordwijk M and Schaik C (2017). The effects of sociability on exploratory tendency and innovation repertoires in wild Sumatran and Bornean orangutans. Scientific Reports 7(1), 15464.

Sheppard CE, Marshall HH, Inger R, Thompson FJ, Vitikainen EI, Barker S, Nichols HJ, Wells DA, McDonald RA and Cant MA (2018). Decoupling of genetic and cultural inheritance in a wild mammal. Current Biology 28(11), $1846-1850$

Slagsvold T and Wiebe KL (2007). Learning the ecological niche. Proceedings of the Royal Society B 274, 19-23.

Spagnoletti N, Izar P and Visalberghi E (2009). Tool use and terrestriality in wild bearded capuchin monkey (Cebus libidinosus). Folia Primatologica 80(2), 142-142.

Spagnoletti N, Visalberghi E, Verderane MP, Ottoni E, Izar P and Fragaszy D (2012). Stone tool use in wild bearded capuchin monkeys, Cebus libidinosus. Is it a strategy to overcome food scarcity? Animal Behaviour 83(5), 1285-1294.

Tennie C, Call J and Tomasello M (2009). Ratcheting up the ratchet: on the evolution of cumulative culture. Philosophical Transactions of the Royal Society B - Biological Sciences 364(1528), 2405-2415, https://doi:10.1098/rstb.2009.0052

Tomasello M (1999). The Cultural Origins of Human Cognition. Cambridge MA: Harvard University Press.

Tomasello M, Krufer A and Ratner H (1993). Cultural learning. Behavioral and Brain Science 16, 495-511.

Torralvo K, Rabelo RM, Andrade A and Botero-Arias R (2017). Tool use by Amazonian capuchin monkeys during predation on caiman nests in a high-productivity forest. Primates 58(2), 279-283.

Tylor EB (1871). Primitive Culture: Researches into the Development of Mythology, Philosophy, Religion, Art, and Custom. London: J. Murray, Vol. 2.

van Schaik CP (1999). The socioecology of fission-fusion sociality in orangutans. Primates 40, 73-90.

van Schaik CP (2010). Social learning and culture in animals. In Kappeler P (ed.), Animal Behaviour: Evolution and Mechanisms. Heidelberg, Berlin: Springer, pp. 623-653.

van Schaik CP (2016). The Primate Origins of Human Nature. Chichester: John Wiley \& Sons, Vol. 2. 
van Schaik CP and Burkart JM (2011). Social learning and evolution: the cultural intelligence hypothesis. Royal Society Philosophical Transactions Biological Sciences 366(1567), 1008-1016.

van Schaik CP, Ancrenaz M, Borgen G, Galdikas B, Knott CD, Singleton I, Suzuki A, Utami SS and Merrill M (2003a). Orangutan cultures and the evolution of material culture. Science 299(5603), 102-105, https://doi:10.1126/science.1078004

van Schaik CP, Fox EA and Fechtman LT (2003b). Individual variation in the rate of use of tree-hole tools among wild orang-utans: implications for hominin evolution. Journal of human evolution 44(1), 11-23, https://doi:10.1016/s00472484(02)00164-1

van Schaik CP, Ancrenaz M, Reniastoeti D, Knott CD, Morrogh-Bernard H, Nuzuar OK, Atmoko S and Noordwijk MA (2009). Orangutan cultures revisited. In Wich SA, Mitra Setia T, Utami Atmoko SA and Van Schaik CP (eds.), Orangutans Compared: Geographic Variation in Behavioral Ecology and Conservation. Oxford: Oxford University Press, pp. $299-309$.

van Schaik CP, Graber S, Schuppli C and Burkart J (2017). The ecology of social learning in animals and its link with intelligence. The Spanish Journal of Psychology 19, 1-12.

van Schaik CP, Pradhan GR and Tennie C (2019). Teaching and curiosity: sequential drivers of cumulative cultural evolution in the hominin lineage. Behavioral ecology and sociobiology $73,2$.

Videan EN (2006). Bed-building in captive chimpanzees (Pan troglodytes): the importance of early rearing. American Journal of Primatology 68, 745-751.

Visalberghi E, Fragaszy DM, Izar P and Ottoni EB (2005). Terrestriality and tool use. Science 308(5724), 951-952; author reply 951-952.

Warner RR (1988). Traditionality of mating-site preferences in a coral reef fish. Nature 335, 719, https://doi:10.1038/ 335719a0

Whitehead H and Rendell L (2014). The Cultural Lives of Whales and Dolphins. Chicago, IL: University of Chicago Press.

Whiten A (2012). Social learning, traditions, and culture. In Mitani JC, Call J, Kappeler PM, Palombit RA and Silk JB (eds), The Evolution of Primate Societies, pp. 682-700.

Whiten A (2017). Culture extends the scope of evolutionary biology in the great apes. Proceedings of the National Academy of Sciences, 201620733.

Whiten A and Mesoudi A (2008). Establishing an experimental science of culture: animal social diffusion experiments. Philosophical Transactions of the Royal Society B - Biological Sciences 363(1509), 3477-3488, https://doi:10.1098/rstb. 2008.0134

Whiten A and van de Waal E (2018). The pervasive role of social learning in primate lifetime development. Behavioral Ecology and Sociobiology 72(5), 80.

Whiten A and van Schaik CP (2007). The evolution of animal 'cultures' and social intelligence. Philosophical Transactions of the Royal Society B - Biological Sciences 362(1480), 603-620, https://doi:10.1098/rstb.2006.1998

Whiten A, Goodall J, McGrew WC, Nishida T, Reynolds V, Sugiyama Y, Tutin CEG, Wrangham RW and Boesch C (1999). Cultures in chimpanzees. Nature 399(6737), 682-685, https://doi:10.1038/21415

Cite this article: Schuppli C, van Schaik CP (2019). Animal cultures: how we've only seen the tip of the iceberg. Evolutionary Human Sciences 1, 1-13. https://doi.org/10.1017/ehs.2019.1 